\title{
BERAPA KEBUTUHAN DIAZEPAM UNTUK MEMENUHI PELAYANAN KESEHATAN DI INDONESIA? STUDI KASUS KONSUMSI DIAZEPAM DI INDONESIA
}

\author{
HOW MUCH OF DIAZEPAM IS NECESSARY IN ORDER TO FULFILL THE HEALTH SERVICE IN INDONESIA? \\ CASE STUDIES OF DIAZEPAM CONSUMPTION IN INDONESIA
}

Nunung Priyatni W

Prodi S2 Ilmu Kesehatan Masyarakat, Fakultas Kedokteran, Universitas Gadjah Mada, Yogyakarta

\section{ABSTRAK}

Diazepam adalah obat esensial golongan benzodiazepin yang penggunaannya diawasi secara nasional dan global, oleh karena itu ketersediaan untuk pelayanan kesehatan harus dapat terpenuhi. Tujuan penelitian untuk mengkaji kebutuhan diazepam dengan menganalisis konsumsi diazepam selama 5 tahun dari tahun 2010 sampai dengan tahun 2014 serta menghitung kebutuhan yang harus tersedia. Penelitian studi kasus dengan pendekatan diskriptif analitik. Menggunakan data sekunder untuk mengkaji penggunaan diazepam selama tahun 2010 sampai dengan tahun 2014. Penggunaan diazepam dihitung berdasarkan data konsumsi, yaitu data produksi, impor dan ekspor. Nilai konsumsi diazepam (dalam kg) per tahun diubah dalam "Define Daily Doses for Statistical purposes" (S-DDD). S-DDD adalah unit teknis pengukuran untuk tujuan analisis statistik dan tidak direkomendasikan untuk dosis peresepan. Menghitung kebutuhan diazepam untuk penderita gangguan jiwa berdasarkan nilai S-DDD. Konsumsi diazepam mengalami penurunan selama tahun 2010 sampai dengan tahun 2014 . Konsumsi tertinggi pada tahun 2010 dan terendah pada tahun 2014, rerata konsumsi diazepam selama 5 tahun sebesar 0,36 S-DDD.Ketersediaan diazepam belum mencukupi untuk kebutuhan penderita gangguan jiwa.Sebagai obat esensial konsumsi diazepam di Indonesia masih rendah, belum mencukupi untuk memenuhi pelayanan kesehatan. Kuantifikasi kebutuhan yang tepat diperlukan untuk memenuhi ketersediaan dan akses pasien mendapat pengobatan.

Kata kunci: diazepam, obat esensial, konsumsi

ABSTRACT

Diazepam is an essential medicine which belongs to benzodiazepine class whose usage is both nationally and globally observed. Thus, the availability of medical service had to be fulfilled. The aim of this research is to study the demand of diazepam by analyzing its consumption for the last 5 years from 2010 to 2014 along with counting the demand that must be available. Case study of this research utilizes the descriptive analytics approach and employing secondary data to review the usage of diazepam within the last 5 years. The consumption of diazepam was counted in accordance with consumption data which are data of production, import and export. The value of its consumption (in kg) per year was converted into "Define Daily Doses for Statistical purposes" (S-DDD). SDDD is the technical measurement unit for the purpose of statistical analysis and not recommended for dosage prescription. The need of diazepam for patients with mental illness is determined by the S-DDD value. Diazepam consumption has experienced a decline from 2010-2014. The highest consumption was in 2010 whereas the lowest was in 2014 and the average consumption of diazepam within the past 5 years was 0,36 S-DDD. The availability of diazepam is not adequate yet for patients with mental illness. As an essential medicine, its consumption in Indonesia is still low to meet the health service. The exact quantification of needs is necessary to attain the availability and patient access for medication.

Keywords: diazepam, essential medicine, consumption

\section{PENDAHULUAN}

Diazepam adalah obat esensial golongan benzodiazepin yang tercantum dalam WHO Essential List of Medicines Edisi 19 (WHO, 2015), Daftar Obat Esensial Nasional (Kemenkes RI, 2015a) serta Formularium Nasional (Kemenkes RI, 2015b), ketersediaannya harus terpenuhi di fasilitas pelayanan kesehatan dasar dan rujukan. Akses mendapatkan kesehatan termasuk mendapatkan obat esensial merupakan hak

\footnotetext{
Korespondensi

Nunung Priyatni W

Prodi S2 Ilmu Kesehatan Masyarakat, Fakultas Kedokteran UGM

Email: priyatni.nunung@gmail.com
}

asasi manusia, sehingga menjadi kewajiban pemerintah untuk menjamin ketersediaannya di fasiltas pelayanan kesehatan.

Tidak semua obat golongan benzodizepin termasuk dalam obat esensial. Terdapat tiga senyawa benzodiazepin yang termasuk esensial yaitu diazepam, lorazepam dan midazolam (WHO, 2015; INCB, 2015). Menurut Formularium Nasional, diazepam dan midazolam harus tersedia difasilitas pelayanan kesehatan tingkat primer dan rujukan, sedangkan ketersediaan lorazepam hanya untuk fasilitas kesehatan rujukan (Kemenkes RI, 2015b). Dengan demikian ketersediaan diazepam harus lebih banyak karena digunakan di semua fasilitas kesehatan. 
Benzodiazepin menimbulkan ketergantungan dan sering disalah gunakan bersama dengan narkotika opioid, alcohol maupun benzodiazepine related drugs (z-drugs) sepertizopiclon, zaleplon dan zolpidem (Jannet al., 2014 dan Casatiet al., 2012). Meskipun sering disalahgunakan, namun pemerintah wajib menjamin ketersediaan untuk penggunaan medis di seluruh fasilitas pelayanan kesehatan.

Penggunaan diazepam dikontrol secara nasional dan global. Secara nasional penggunaan diazepam diatur melalui UndangUndang Nomor 5 Tahun 1997 tentang Psikotropika, sedangkan secara global melalui Convention on Psychotropic Substance of 1971, yang telah diratifikasi melalui Undang-Undang Nomor 8 Tahun 1997 tentang Pengesahan Konvensi Psikotropika 1971. Pengaturan tersebut bertujuan untuk menjamin ketersediaannya guna kepentingan kesehatan dan ilmu pengetahuan serta mencegah terjadinya penyalahgunaan.

Diazepam diindikasikan untuk terapi kecemasan (ansietas) dalam penggunaan jangka lama, karena mempunyai masa kerja panjang (Finkel et al., 2009). Selain itu juga sebagai sedatif dan keadaan psikosomatik yang ada hubungan dengan rasa cemas. Selain sebagai antiansietas, diazepam digunakan sebagai hipnotik, antikonvulsi, pelemas otot dan induksi anastesi (Katzung et al., 2012). Diazepam juga digunakan untuk preeklampsia dan eklampsia yang diberikan secara intravena dengan dosis 10 mg (Kemenkes RI, 2007). Untuk itu ketersediaan yang memadai sesuai kebutuhan medis harus terpenuhi di semua tingkatan fasilitas kesehatan.

\section{METODE}

Penelitian studi kasus dengan pendekatan deskriptif analitik melalui penelahaan data sekunder dan wawancara mendalam untuk menguatkan data sekunder. Penelitian dilakukan di Yogyakarta dan Jakarta pada bulan April 2016. Data yang diperlukan adalah data produksi, impor dan ekspor diazepam selama periode tahun 2010-2014 yang diambil dari Technical Report Psychotropic INCB tahun 2012 dan 2014 maupun dari Direktorat
Produksi dan Distribusi Kefarmasian Kementerian Kesehatan RI; data penduduk Indonesia dari tahun 2010 sampai dengan tahun 2014; nilai S-DDD diazepam sebagai ansiolitik (10,00 mg) yang diambil dari Technical Report Psychotropic INCB tahun 2014.

Penggunaan diazepam dihitung dengan metode konsumsi menggunakan data produksi, impor dan ekspor setiap tahunnya dari tahun 2010-2014. Perhitungan konsumsi nasional per tahun berdasarkan jumlah diazepam $(\mathrm{kg})$ yang diimpor dikurangi yang diekspor. Apabila ada data produksi, maka ditambahkan. Apabila tidak ada data ekspor dan produksi, maka konsumsi dihitung berdasarkan jumlah yang diimpor. Nilai konsumsi (dalam $\mathrm{kg}$ ) per tahun kemudian diubah dalam "Define Daily Doses for Statistical purposes" (S-DDD). S-DDD adalah unit teknis pengukuran untuk tujuan analisis statistik dan tidak direkomendasikan untuk dosis peresepan (INCB, 2015). Nilai konsumsi dalam satuan S-DDD dihitung melalui jumlah konsumsi per tahun (dalam mg) dibagi dengan jumlah penduduk per seribu pada tahun tersebut dibagi dengan jumlah hari per tahun (365 hari) dibagi dengan nilai standar S-DDDdiazepam sebagai ansiolitik (10,00 mg).

Menghitung kebutuhan diazepam untuk penderita gangguan jiwa berdasarkan rerata prevalensi penderita gangguan jiwa di Indonesia 1,7 permil hasil Riset Kesehatan Daerah tahun 2013 (Kemenkes RI, 2013).

\section{HASIL DAN PEMBAHASAN}

Nilai impor dan ekspor diazepam dari Technical Report INCB maupun dari Direktorat Produksi dan Distribusi Kefarmasian dan Alkes Kementerian Kesehatan RI tidak ada perbedaan, data pada INCB merupakan nilai pembulatan dari Laporan Kementerian Kesehatan RI, sehingga dipilih data yang berasal dari Kementerian Kesehatan RI. Indonesia belum memproduksi bahan baku diazepam, sehingga untuk produksi sediaan jadi perlu mengimpor dari beberapa negara seperti Italia, Republik Rakyat Cina, India, dan Denmark. Sedangkan ekspor sediaan jadi diazepam ke Kamboja, Hongkong, Selandia Baru, Singapura, 
Tabel I. Konsumsi diazepamdi Indonesia Tahun 2010-2014 (dalam kg dan S-DDD)

\begin{tabular}{ccccc}
\hline Tahun & Impor $\mathbf{( k g )}$ I & Ekspor(kg) E & Konsumsi (kg) I-E & Konsumsi (S-DDD) \\
\hline 2010 & 562,54 & 46,234 & 516,051 & 0,60 \\
2011 & 579,103 & 272,489 & 306,614 & 0,35 \\
2012 & 745,53 & 483,0 & 262,530 & 0,29 \\
2013 & 914,972 & 497,967 & 417,275 & 0,46 \\
2014 & 314,995 & 204,659 & 110,336 & 0,12 \\
Rerata konsumsi & & & & 0,36 \\
(S-DDD) & & & & \\
\hline
\end{tabular}

Sumber data : Kemenkes RI, 2015, diolah oleh peneliti.

Tabel II. Konsumsi alprazolam di Indonesia tahun 2010-2013 (dalam kg dan S-DDD)

\begin{tabular}{ccccc}
\hline Tahun & Impor (I) kg & Ekspor (E) kg & $\begin{array}{c}\text { Konsumsi (kg) = I- } \\
\text { E Konsumsi (S-DDD) }\end{array}$ \\
\hline 2010 & 38 & 0 & 38 & 0,44 \\
2011 & 66 & 0 & 66 & 0,75 \\
2012 & 57 & 0 & 57 & 0,66 \\
2013 & 48 & 2 & 46 & 0,37 \\
Rerata konsumsi & & & & 0,56 \\
(S-DDD) & & & & \\
\hline
\end{tabular}

Sumber data : INCB (2012a) dan INCB (2014), diolah oleh peneliti. S-DDD alprazolam = $1 \mathrm{mg}$

Srilanka dan Taiwan (BPOM, 2016 wawancara mendalam, data tidak dipublikasi).

Konsumsi diazepam menurun dari tahun 2010-2014, namun masih dibawah 1 ton. Rerata konsumsi tertinggi pada pada tahun 2010 sebesar 516,051kg (0,60 S-DDD) dan tahun 2014 sebesar 110,336 kg. Konsumsi diazepam (Tabel I).

Selama periode 5 tahun konsumsi diazepam di Indonesia mengalami penurunan. Konsumsi tertinggi pada tahun 2010 sebesar 0,60 S-DDD dan terendah pada tahun 2014 sebesar 0,12 S-DDD. Rerata konsumsi diazepam pada tahun 2010-2014 sebesar 0,36 S-DDD, terjadi penurunan sebesar $80 \%$ Jika dibandingkan dengan rerata konsumsi global selama periode tahun 2011-2013 sebesar 4,14 SDDD (INCB, 2015), maka rerata konsumsi diazepam di Indonesia pada periode tahun yang sama hanya 9\% dari konsumsi global. Rerata konsumsi global pada tahun 2004-2006 sebesar 5,15 S-DDD, terjadi penurunan sebesar 20\% dibanding konsumsi periode tahun 2011-2013. Penurunan konsumsi terbesar di kawasan Asia
$(70 \%)$ dan Amerika (44\%), sedangkan di kawasan Afrika dan Oceania mengalami peningkatan, berturut-turut $70 \%$ dan $11 \%$ (INCB, 2015). Konsumsi diazepam yang rendah mengindikasikan rendahnya ketersediaan untuk pelayanan kesehatan serta kemungkinan penggunanya beralih ke senyawa lain.

Konsumsi diazepam rendah dan ketersediaannya terbatas, apakah pasien tidak diobati dengan diazepam atau kebutuhan diazepam digantikan oleh obat lain yang lebih baik dan lebih tersedia? Meskipun ketersediaan diazepam rendah, nampaknya hal tersebut tidak menimbulkan gejolak di pelayanan kesehatan karena masih ada pilihan lain. Rerata konsumsi diazepam 0,46 S-DDD pada tahun 2013, penderita gangguan jiwa di Indonesia pada tahun 2013 sebesar 1,7 permil, berarti baru 27\% penderita gangguan jiwa yang mendapatkan pengobatan dengan diazepam sehingga masih ada sekitar $73 \%$ yang belum mendapatkan terapi dengan diazepam atau kemungkinan diterapi dengan obat lain. Padahal diazepam masih digunakan untuk terapi yang lain seperti 
untuk induksi anastetik, pelemas otot dan antiepileptik, sehingga kebutuhan minimal diperkirakan mencapai 2 S-DDD.

Tren penggunaan diazepam kemungkinan sudah beralih ke alprazolam. Secara farmakologi, diazepam merupakan kelompok benzodiazepin dengan kerja panjang dengan waktu paruh 20-80 jam, sedangkan alprazolam 12-15 jam (Katzung, 2012), sehingga penggunaan diazepam dapat mengganggu aktivitas pasien karena obat golongan benzodiazepin mempunyai efek hipnosis yang mengakibatkan pasien mengantuk. Konsumsi alprazolam di Indonesia selama tahun 2010-2013 menunjukkan adanya peningkatan, meskipun konsumsi masih dibawah 1 S-DDD (INCB, 2012adan INCB, 2014, data diolah), sedangkan konsumsi diazepam menunjukkan adanya penurunan.Hal ini mengindikasikan adanya peralihan penggunaan diazepam ke alprazolam. Diazepam relatif aman dan murah dibanding dengan alprazolam, tetapi mengapa penggunaannya menurun, apakah dokter lebih suka meresepkan alprazolam dari pada diazepam. Kajian lebih lanjut perlu dilakukan untuk mengungkap alasan dokter lebih memilih meresepkan alprazolam dari pada diazepam. Konsumsi alprazolam disajikan pada Tabel II.

Selain beralih menggunakan alprazolam, ada kemungkinkan penggunaan non benzodiazepin (benzodiazepin related drugs) seperti zopiclon, zolpidem, zaleplon dan eszopiclone, karena obat tersebut sudah masuk dalam sistem klasifikasi WHO Anatomic Therapeutic Classification, dengan kode N05CF. Kode N adalah sistem syaraf, N05 adalah psikoleptik, N05C adalah hipnotik dan sedatif, dan N05CF adalah benzodiazepine related drugs (WHO, 2014). Golongan ini dikenal dengan nama $z$-drugs, mempunyai masa kerja pendek dan bekerja pada reseptor benzodiazepin (Katzung, 2012). Tren penggunaan zolpidem dan zopiclone di Denmark selama periode 1997-2008 mengalami peningkatan, sedangkan benzodiazepin mengalami penurunan (Holm et $a l, 2012)$. Di Kanada terjadi perubahan dalam praktik peresepan benzodiazepin, khususnya untuk pasien tua peresepan dengan benzodiazepine menurun, namun penggunaan $z$-drugs meningkat, dan tren serupa ditemukan di berbagai kajian internasional lain (Pollmann et al, 2015).

Sediaan $z$-drugs dalam bentuk merk dagang sudah tersedia di Indonesia, namun seberapa besar penggunaannya belum diketahui secara pasti, sehingga kajian penggunannya di Indonesia menarik untuk diteliti, khususnya di fasilitas kesehatan swastakarena $z$-drugs belum diakui sebagai obat esensial.

Rendahnya ketersediaan dapat disebabkan karena kurang tepatnya perhitungan kebutuhan diazepam. Kuantifikasi kebutuhan psikotropika dapat dilakukan dengan metode konsumsi, metode berbasis pelayanan dan metode morbiditas (Suryawati, 2011; INCB, 2012b). Masing-masing metode memerlukan data pendukung yang tepat. Metode kuantifikasi berdasarkan morbiditas merupakan metode yang paling direkomendasikan agar pelayanan kesehatan terpelihara dengan baik. Tingkat konsumsi adekuat dan inadekuat untuk psikotropika belum ditetapkan oleh INCB (INCB, 2016), dan hal ini sangat tergantung dari penyakit yang diobati, sehingga perhitungan kebutuhan psikotropika yang adekuat dapat menggunakan metode morbiditas.

Perhitungan metode morbiditas dilakukan dengan menghitung jumlah obat yang dibutuhkan rata-rata per kasus dikalikan dengan jumlah kasus setiap tahun (WHO, 2012b). Permasalahannya data morbiditas yang memerlukan diazepam tidak tersedia. Metode morbiditas dapat terpenuhi apabila standar pengobatan tersedia dan dipatuhi secara konsisten, serta pendataan kasus morbiditas terkait dengan penggunaan diazepam tersedia. Menurut Formularium Nasional, diazepam diindikasikan untuk terapi ansietas, epilepsi, sedasi dan tindakan pra anastesi (Kemenkes RI, 2015b). Untuk itu diperlukan pendataan masing-masing kasus tersebut untuk dapat menentukan kebutuhan diazepam yang tepat. Hal ini sesuai rekomendasi INCB dalam Laporan tahunan tahun 2015 tentang penggunaan psikotropika khususnya benzodiazepin, bahwa negara disarankan melakukan monitoring lebih ketat terhadap 
konsumsi benzodiazepin dan menjamin peresepan sesuai dengan pedoman pengobatan dan penggunaan psikotropika yang rasional (INCB, 2016).

Jika kuantifikasi kebutuhan diazepam menggunakan metode konsumsi, maka konsekuensinya harus tersedia data pendukung berupa penggunaan diazepam per tahun di fasilitas kesehatan, data impor dan ekspor oleh industri dan PBF, serta stok akhir tahun di fasilitas kesehatan, distributor dan industri farmasi. Jika data pendukung tersebut tersedia, maka kebutuhan diazepam atau pengadaan tahun berikutnya dapat dihitung denganmenjumlahkan rerata penggunaan per tahun selama 3 tahun sebelumnya, ditambah $10 \%$ dari rerata penggunaan per tahun ditambah dengan rencana ekspor tahun berikutnya, dan dikurangi sisa stok pada akhir tahun sebelumnya.

Perhitungan kebutuhan yang tidak tepat menyebabkan ketersediaan diazepam di fasilitas kesehatan tidak terpenuhi, terutama di fasilitas kesehatan swasta, yang akhirnya terjadi kekosongan obat. Ketersediaan diazepam injeksi di puskesmas seluruh Indonesia pada Triwulan IV tahun 2015 sebesar 51,5\% (Kemenkes RI, 2016), yang berarti masih diperlukan 49,5\% diazepam injeksi yang harus disediakan. Jadi memang masih diperlukan tambahan ketersediaan diazepam untuk pelayanan kesehatan.

Jika penderita gangguan jiwa di Indonesia pada tahun 2013 sebesar 1,7 permil (Kemenkes, 2013), maka kebutuhan diazepam untuk terapi penderita gangguan jiwa memerlukan sekitar $1.543,9 \mathrm{~kg}$. Pada Tabel I tersebut nampak bahwa konsumsi diazepam pada tahun 2013 sebesar 417,275 kg, masih ada kekurangan sekitar $1.100 \mathrm{~kg}$ diazepam untuk memenuhi kebutuhan pelayanan kesehatan. Untuk memenuhi ketersediaan dan konsumsi di fasilitas kesehatan, maka nilai impor harus dinaikkan dua kali namun nilai ekspor dipertahankan. Diperlukan adanya kebijakan impor dan ekspor untuk menjaga keseimbangan ketersediaan dalam negeri.

\section{KESIMPULAN.}

Sebagai obat esensial konsumsi diazepam selama tahun 2010 sampai dengan tahun 2014 mengalami penurunan. Ketersediaan diazepam belum memenuhi kebutuhan pelayanan kesehatan, yang berdampak pada akses pasien mendapatkan pengobatan yang rasional. Kuantifikasi kebutuhan yang tepat diperlukan untuk menjaga ketersediaan dalam rangka memenuhi kebutuhan pelayanan kesehatan.

\section{UCAPAN TERIMA KASIH}

Ucapan terima kasih kepada Program S3 Fakultas Kedokteran UGM melalui MoU S3/014/M/05/04/01.16 yang telah mendukung penelitian ini.

\section{DAFTAR PUSTAKA}

Casati, A., Sedafov, R., Pfeiffer, T., Gerschel, 2012, Misuse of medicine in The European Union.A Systematic Review of the literature, Euro Addict Res,18:228-245.

Finkel, R., Clark, MA., Cubeddu, LX., Harvey, RA., Champe, PC, 2009,Pharmacology 4th edition,Walters Kluwer, Philadelphia :105-107.

Holm, E., Fosbol, E., Pedersen, H., et al., 2012, Benzodiazepine use in Denmark 19972008, European Geriatric Medicine, 3 : 299303.

International Narcotics Control Board, 2016,INCB Report 2015,Vienna, Austria $: 101$.

International Narcotics Control Board, 2015,Availability of Internationally Controlled Drugs : Ensuring Adequate Access for Medical and Scientific Purposes, Vienna, Austria.

International Narcotics Control Board and United Nations, 2014,Psychotropic Subtances 2013, Statistic for 2013 Assessments of Annual Medical and Scientific Requirements, United Nations, New York.

International Narcotics Control Board and United Nations, 2012a,Psychotropic Subtances 2011, Statistic for 2011 Assessments of Annual Medical and Scientific Requirements, United Nations, New York.

International Narcotics Control Board and United Nations, 2012b,Guide on Estimating 
Requirements for Subtances under International Control, United Nations, New York.

Jann, M., Kennedy, WK., Lopez, G. , 2014, Benzodiazepines : a major component in unintentional prescription drugs overdosis with analgesics,Journal Pharmacy Practise, 27(1): 5-16.

Katzung, BG., Masters, SB., Trevor, AJ., 2012,Basic \& Clinical Pharmacology, edisi 12, Mc Grow-Hill Medical, New York : 373-387.

Kementerian Kesehatan RI, 2016, Profil Kesehatan Indonesia tahun 2015, Kementerian Kesehatan RI, Jakarta.

Kementerian Kesehatan RI, 2015a, Keputusan Menteri Kesehatan Republik Indonesia Nomor HK 02.02/Menkes/320/2015 tentang Daftar Obat Esensial Nasional 2015. Kementerian Kesehatan, Jakarta.

Kementerian Kesehatan RI, 2015b, Keputusan Menteri Kesehatan Republik Indoneisa Nomor HK.0202/Menkes/523/2015 tentang Formularium Nasional, Kementerian Kesehatan, Jakarta.

Kementerian Kesehatan RI, 2013,Riset Kesehatan Dasar Tahun 2013. Kementerian Kesehatan RI, Jakarta. Diakses di www.depkes.go.id pada tanggal 20 Desember 2015.

Kementerian Kesehatan RI, 2007,Pedoman pengobatan dasar di puskesmas,Kementerian Kesehatan RI, Jakarta.
Management Sciences for Health, 2012,MDS-3 Managing access to medicine and health technologies, Management Sciences for Health, Arlington.

Pollmann, AS., Murphy, AL., Bergman, JC., Gardner, DM., 2015, Deprescribing benzodiazepines and Z-drugs in community-dwelling adults : s scoping review, BMC Pharmacology \& Toxicology 16:19 DOI 10.1 1186/s40360-015-009-8, open access.

Suryawati,S., 2011, Improving access to narcotic analgesics, the international control system and options for quantification method. Jurnal Manajemen Pelayanan Kesehatan, 4 (1): 3-10.

Word Health Organization, 2015, Essential List of Medicine. Word Health Organization,Geneva. http://www.who.int/medicines/publicatio ns/essentialmedicines/en/. Diakses tanggal 30 November 2015.

World Health Organization, 2014,WHO Collaborating Centre for Drug Statistics Methodology,ATC/DDD Index 2014, Norwegian Institute of Public Health, http://www.whocc.no/atc_ddd_index/, diakses tanggal 22 Juli 2016. 